\title{
ON THE OXIDE FILMS EFFECT ON THE THERMAL PROCESSES IN THE PARTICLE-SUBSTRATE SYSTEM DURING PLASMA SPRAYING
}

\author{
G. GROMYKO and G. ZAYATS \\ Institute of Mathematics of National Academy of Sciences of Belarus \\ Surganov 11, 220072, Minsk, Belarus \\ E-mail: grom@im.bas-net.by; zayats@im.bas-net.by
}

Received October 1, 2001; revised November 12, 2002

\begin{abstract}
In the present paper one mathematical model of the thermal processes in the particlesubstrate system under plasma spraying is developed. The energy equation is solved for both particle and substrate regions using the adjoint conditions for the temperature. Main attention is paid to investigation of the temperature in contact of the particle with substrate. The oxide films effect on the surface substrate taking onto account thermal resistance of oxide is simulated. Numerical results for the heat transfer process and the effect of some important processing parameters have been discussed. Numerical algorithms were realized in the form of applied programs complex.
\end{abstract}

\section{INTRODUCTION}

Thermal plasma spraying has been paid much attention to lately. The industrial significance of the process lies in the possibility of the deposition of melted and accelerated micron sized particles on a substrate, in order to produce a mechanically strong and corrosion-resistant coating on pre-shaped parts. Principal way of destruction of plasma sprayed coating is insufficient strength of coating cohesion with substrate material. Considering the above mentioned, the problem of creation of plasma spray coatings with given properties is important. The mathematical simulation is one of directions used at research of processes, happening at plasma spraying. The results of liquid particle impact simulation on a hard substrate are represented in a number of works, such as $[1 ; 7 ; 8]$. Works of the authors $[3 ; 4]$ are devoted to simulation 
of a viscous incompressible particle behavior during thermal plasma spraying. The simulation of a viscous compressible particle movement is reflected in papers [2]. The main attention in these papers is given to joint solution of the hydrodynamic problem (definition of the flattening region of molten particle) and thermal problem (finding of a temperature field in the particle-substrate region).

In the given paper simulation of the thermal processes is accomplished taking into account a number of environment parameters and thermal properties of evaporated materials and substrate.

In our model the particle looks like the spread disk, thermal properties of the particle and the substrate depend on the temperature, and the calculation of the temperature field is carried out considering various heat sources (these are convective heat transfer and action of pressure forces). Also it is necessary to take into account the fact, that for the majority of materials used in plasma spraying thermal characteristic in liquid and hard states considerably differ from each other. It is supposed, that the heating of a particle surface by plasma jet takes place owing to the forced convective and radiation heat exchange.

It is known [6], that contact temperature is one of the main parameters necessary for estimation of chemical interactions between an evaporated particle and a substrate and for definition of strength of an obtained coating. In the given paper research of contact temperature depending on a substrate heating, on a particle overheating, on presence of an oxide film on a substrate surface and other factors attendant the given process are reduced.

Special attention to research of influence of an oxide films for a temperature field in the particle-substrate system is given.

\section{MATHEMATICAL MODEL}

The mathematical model developed in this paper is based on the following assumptions:

1. The particle represents the spread disk. At the initial instant it is molten and its temperature can be higher than the melting temperature of the particle material;

2. The substrate represents a body-cylinder with the initial temperature less than the melting temperature of the substrate. The substrate is selected thick enough in comparison to the spread disk and from such condition, that the bottom of a substrate does not get warm;

3. The surface of a substrate is smooth;

4. There is an oxide film on the surface of a substrate;

5. Temperature originating in the area of contact between the particle and the substrate is less than melting temperatures of the particle and the substrate. 
Conditions $1-5$ determine model of the thermal process. Schematic picture of the considered area is presented in Fig. 1a). While using the indicated conditions the problem of the particle solidification on a substrate is equivalent to the research of temperature fields in the nonuniform cylinder consisting of several parts (particle, substrate and oxide film between them), which materials have various thermophysical properties.

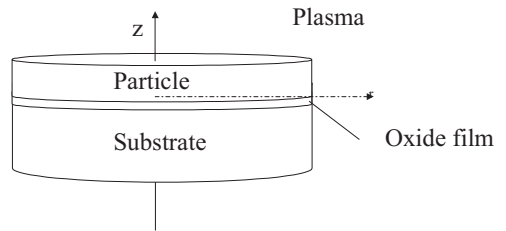

a)

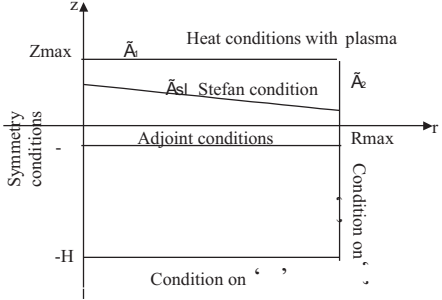

b)

Figure 1. a) Schematic region of the particle-substrate, b) the boundary conditions for the thermal problem.

Taking into account assumptions $1-5$ and the fact that the thermophysical characteristics of the materials of the particle and the substrate can depend on temperature, we shall determine a temperature field in the particle-substrate system considering symmetry of the task by a two-dimensional non-stationary quasilinear heat conduction equation in a cylindrical coordinate system $(r, z)$ :

$$
\rho_{k} c_{k}(T) \frac{\partial T_{k}}{\partial t}=\frac{1}{r} \frac{\partial}{\partial r}\left(r \lambda_{k}(T) \frac{\partial T_{k}}{\partial r}\right)+\frac{\partial}{\partial z}\left(\lambda_{k}(T) \frac{\partial T_{k}}{\partial z}\right)+Q_{k}
$$

where $T_{k}=T(r, z, t)$ is temperature, $\rho_{k}, c_{k}, \lambda_{k}$ are density, specific heat, heat conduction coefficient respectively ; the index $k$ corresponds: 0 - a substrate, 1 - a molten particle part, 2 - a solid particle part, 3 - an oxide film; $Q_{1}$ represents an amount of heat allocated as a result of convection, of pressure influence or presence at the particle of some heat source, $Q_{k}=0(k=0,2,3)$.

We should note, that the particle can be superheated at an initial stage of its interaction with the substrate. The overheating essentially influences temperature in contact in real processes of plasma spraying.

Thermal boundary conditions on the free surface $\widetilde{A}_{1}, \widetilde{A}_{2}$ (Fig. 1b) reflect the effect of the environment on the particle. Heating or subsequent cooling of a particle surface by plasma jet takes place as a result of the forced convective and radiation heat exchange. Here we consider two conditions: the heat exchange condition( Newton's law)

$$
\left.\lambda_{k}(T) \frac{\partial T_{k}}{\partial n}\right|_{\widetilde{A}_{i}}=\left.a_{T}\left(T_{k}-T_{g}\right)\right|_{\widetilde{A}_{i}}(k=1,2 ; i=1,2)
$$


or the heat exchange condition with radiation

$$
\left.\lambda_{k}(T) \frac{\partial T_{k}}{\partial n}\right|_{\widetilde{A}_{i}}=\left.a_{T}\left(T_{k}-T_{g}\right)\right|_{\widetilde{A}_{i}}+\left.\beta \sigma_{b}\left(T_{k}^{4}-T_{g}^{4}\right)\right|_{\widetilde{A}_{i}}(k=1,2 ; i=1,2),
$$

where $\beta$ is emissivity, $\sigma_{b}$ is Stefan-Boltzmann constant, $\partial T \backslash \partial n$ is derivative along the normal to surface, $\alpha_{T}$ is coefficient of heat transfer. In the literature various technique are proposed for defining $\alpha(T)$. We use a relatively simple expression $\alpha(T)=N u \cdot \lambda_{g} /\left(2 R \sqrt{f_{n}}\right)$, where $f_{n}$ is the coefficient of powder shape, $R$ is a radius of spread disk, $\lambda_{g}$ is the coefficient of heat conductivity of plasma under plasma temperature $T_{g}, N u$ is Nusselt number. For definition Nusselt number we shall use one modification of Rantz-Marshall formula which is used under consideration of the heat transfer between the particles and plasma jet: $N u=2 \lambda_{k} \lambda_{g}+B \cdot R e^{0.5} / P_{r}^{n}\left(\rho_{g} \mu_{g} / \rho \mu\right)^{0.2}, \mu$ is dynamic viscosity, $R e, P$ are Reynolds number and Prandle number respectively.

On the symmetry line $r=0$ the conditions of a symmetry are used.

The definition of the problem for temperature field in the particle-substrate system will be complete, if we give the boundary conditions on the phases boundary and on the interface of the environments. As a result of falling of the molten particle on a cold substrate there is a step-by-step solidification of the particle and there is a relative interface of phases in the particle - the line separating the molten part of the particle from its hardened part, which will be defined during solution of the task.

It is known [6], that the thermal stream in the perpendicular direction to the substrate is 3-6 orders larger, than in the radial direction. It will be sufficient to consider one-dimensional Stefan problem: on the solid-melt interface $z=F(r, t)$ Stefan condition is satisfied

$$
\left.\left(\lambda_{1}(T) \frac{\partial T_{1}}{\partial z}\right)\right|_{z=F(r, t)}-\left.\left(\lambda_{2}(T) \frac{\partial T_{2}}{\partial z}\right)\right|_{z=F(r, t)}=L_{m} \rho_{1} \frac{\partial F}{\partial t}
$$

where $L_{m}$ is melting heat.

Let's also assume, that super-cooling of the liquid phase on the solid-melt interface is equal to 0 , i.e. the temperatures of solid and liquid phases on the solid-melt interface are equal: $T_{1}=T_{2}=T_{m}$ on $z=F(r, t)$.

Considering the task about solidification of the particle on the substrate, we suppose, that temperature, originating in the area of contact between the particle and the substrate, is less than the melting temperature of the particle and the substrate. Therefore, the melt of the substrate misses.

The line $z=0$ is a line of interface of two mediums with various thermophysical properties and there are no sources and sinks of heat on the substrate. Here it is pertinent to spot adjoint boundary conditions including equality of heat flows. However, the oxide film presenting on a substrate surface, has a thermal resistance, which prevents from penetration of heat into the substrate. 
In this connection we shall consider two possible models which are taking into account influence of an oxide film, depending on thickness of the oxide film and accuracy of the expected results.

I. As the thickness of the oxide film is small, its sizes can be neglected for rough calculations. In this case on the contact line of the particle with the substrate we shall determine the following condition:

$$
\left.\left(\lambda_{k}(T) \frac{\partial T_{k}}{\partial z}\right)\right|_{z=0^{+}}=\left.\left(\lambda_{0}(T) \frac{\partial T_{0}}{\partial z}\right)\right|_{z=0^{-}}=\frac{1}{R}\left(T_{k}(r, 0, t)-T_{0}(r, 0, t)\right)
$$

Here $R=\delta / \lambda_{3}$ is heat resistance of the oxide film, $\delta$ is the thickness of the oxide film. This condition reflects the fact, that temperature on the line $z=0$ suffers a jump.

Following the assumption 2, on the bottom of the substrate $z=-H$ the temperature is not varied and is equal to the temperature at an initial moment. Thus, the thermal task in the particle-substrate system is formulated. This task implicitly takes into account thickness of the oxide film.

II. For more precise definition of the contact temperature or in that case when the thickness of the oxide film is significant, we shall present the problem as the task about coupling of three environments with various thermophysical properties: particle - oxide film - substrate.

On the contact line of the particle with the oxide film we consider equality of the heat flows and temperatures:

$$
\left.\left(\lambda_{k}(T) \frac{\partial T_{k}}{\partial z}\right)\right|_{z=0^{+}}=\left.\left(\lambda_{3}(T) \frac{\partial T_{3}}{\partial z}\right)\right|_{z=0^{-}}, T_{k}(r, 0, t)=T_{3}(r, 0, t)(k=1,2) .
$$

Inside the oxide film $\left(r \in\left[0, R_{\max }\right], z \in(-\delta, 0)\right)$ the distribution of heat may be written by the equation (2.1) under $k=3$.

The adjoint conditions on the line $z=-\delta$ are the following

$$
\left.\left(\lambda_{3}(T) \frac{\partial T_{3}}{\partial z}\right)\right|_{z=-\delta^{+}}=\left.\left(\lambda_{0}(T) \frac{\partial T_{0}}{\partial z}\right)\right|_{z=-\delta^{-}}, \quad T_{3}(r,-\delta, t)=T_{0}(r,-\delta, t) .
$$

Thus, represented model, obviously, takes into account the thickness and the thermophysical properties of the oxide film.

Having selected the initial particle radius $R$ as the feature value, we shall enter dimensionless variables and we shall consider the non-dimensionalization process. 


\section{NUMERICAL METHOD}

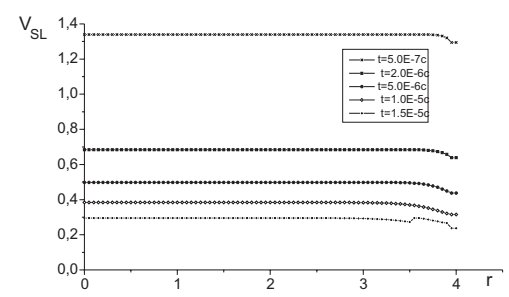

a)

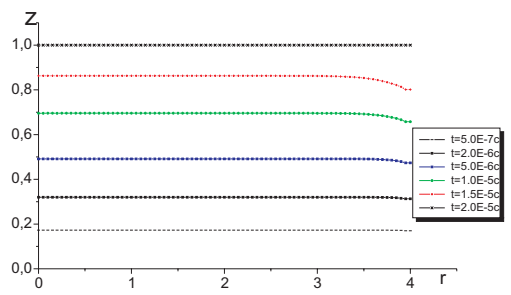

b)

Figure 2. a) Velocity of solid-liquid interface in various instants, b) position of solid-liquid interface in various instants.

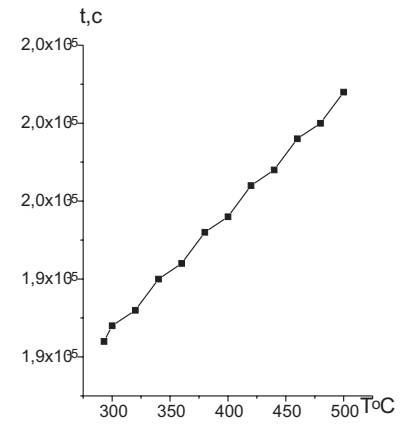

a)

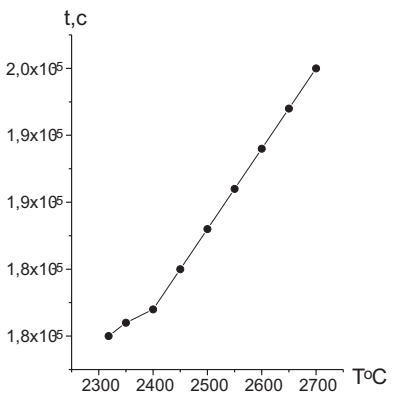

b)

Figure 3. Dependence of the time of complete solidification of the particle on a) initial temperature of the substrate, b) initial temperature of the molten particle.

The finite-difference method was applied for numerical solution of the problem. The flow region is covered with a uniform grid, on which the finitedifference scheme was considered.

Implementation of these schemes was carried out with the help of iterative processes of the variable directions. The iterations were solved by the factorization method (to the contact line $z=0$ ). The numerical algorithm on each time step includes the following stages:

1. definition of the solid-melt interface,

2. solution of the task by the method of counter chaser in a hard part of the particle and substrate with usage of the adjoint conditions on a contact line,

3. solution of the task by the method of direct chaser in a liquid region of the particle with usage of the conditions at the solid-melt interface and of the heat exchange conditions, 


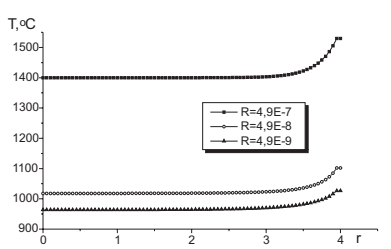

$t=1.0 \times 10^{-6} c$, particle

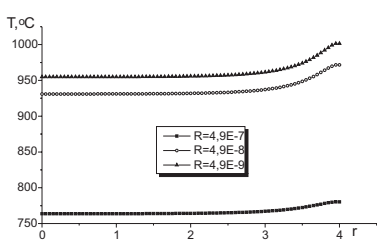

$t=1.0 \times 10^{-6} c$, substrate

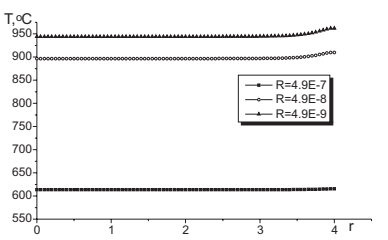

$t=2.0 \times 10^{-6} c$, particle

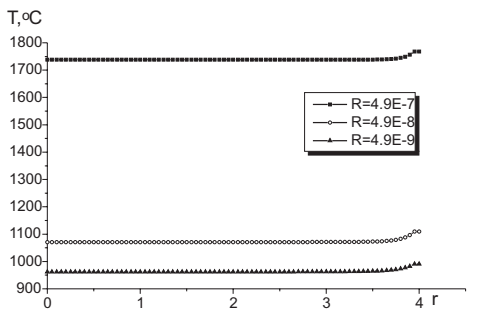

$t=2.0 \times 10^{-6} c$, substrate

Figure 4. Influence of the oxide films on the contact temperature in any time moments.

4. comparison of iterations on given small number, improvement of iterations or transition to the next time step,

5. obtaining of the results as the tables and graphs. The complex of applied programs is written in Fortran.

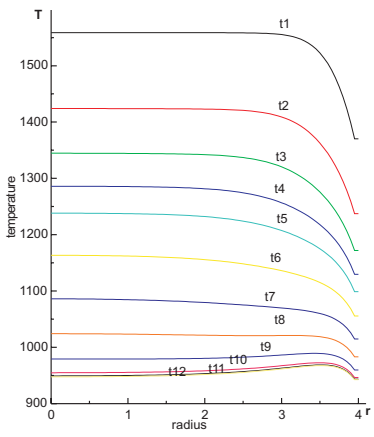

a)

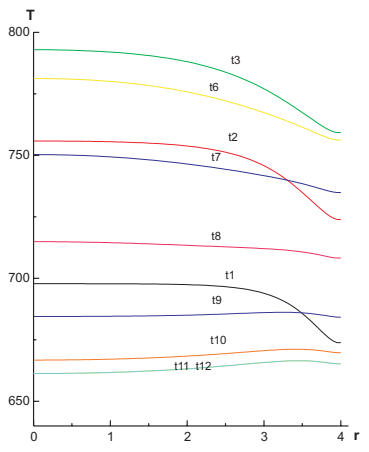

t)

Figure 5. Dependence of contact temperature on time at presence of a film on the substrate surface: a) in particle, b) in substrate.

\section{RESULTS AND DISCUSSION}

Our model allows to calculate the temperature fields in the particle and the substrate, contact temperature and front of solidification at arbitrary mo- 


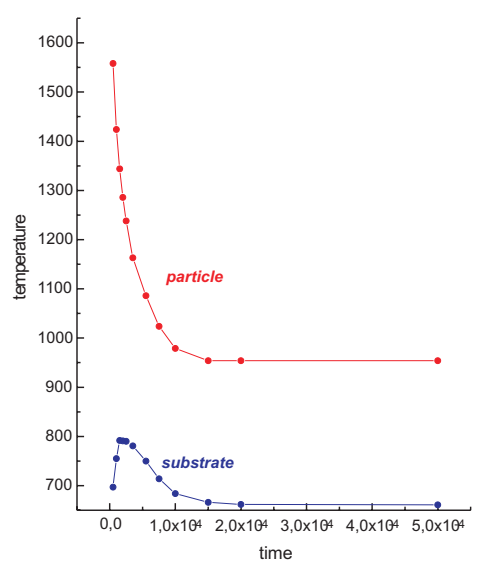

Figure 6. Variation of contact temperature in point $(0,0)$.

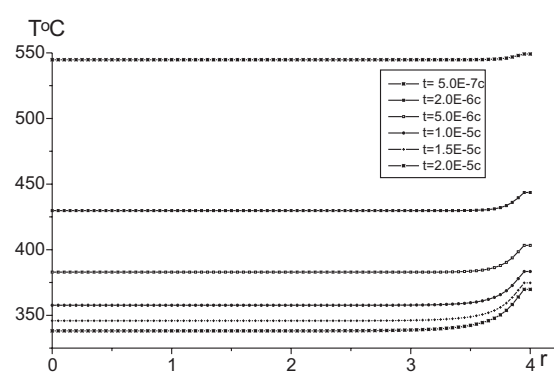

Figure 7. Contact temperature in various instants without the registration of the thermal resistance of the oxide film.

ments. The influence of the oxide films on the contact temperature may be investigate. We present some numerical results of the mathematical simulation. Dynamics of the solidification of the molten (superheated) particle of aluminum oxide $\mathrm{Al}_{2} \mathrm{O}_{3}$ which looks like the spread disk with size [4mkm, $\left.1 \mathrm{mkm}\right]$ after its impingement onto a solid steel substrate in conditions of plasma $A r 80 \mathrm{H}_{2} 20$ at temperature $2400^{\circ} \mathrm{K}$ was investigated. Values of thermophysical parameters of the particle, substrate and plasma which depend on temperature, were taken according to [5] (Tables 1-3).

Table 1.

Parameters used in computations.

\begin{tabular}{lll} 
Stefan-Boltzmann constant & $\sigma_{b}\left(\mathrm{Wm}^{-2} \mathrm{k}^{-1}\right)$ & $5.67 \times 10^{8}$ \\
Initial particle temperature & $T_{1, \text { in }}(K)$ & 3000 \\
Initial substrate temperature & $T_{0, \text { in }}(K)$ & 298 \\
Melting temperature & $T_{m}(K)$ & 2318 \\
Splat radius & $R(m)$ & $4.0 \times 10^{-5}$ \\
Melting heat & $L_{m}\left(\mathrm{~J} / \mathrm{m}^{3}\right)$ & $1.1 \times 10^{6}$ \\
Heat resistance & $R\left(\mathrm{~m}^{2} / \mathrm{s}\right)$ & $4.9 \div 8 \times 10^{-7}$ \\
Thickness of oxide film & $\delta(\mathrm{m})$ & $1.5 \div 5 \times 10^{-6}$ \\
\hline
\end{tabular}

Graphics given below illustrate availability of the offered model. The results of simulation of solid-liquid interface velocity and of solid-liquid interface position in various instants without registration of the thermal resistance of the oxide film are represented in Fig. 2.

In Fig. 3 it is shown, that it is possible to regulate the time of complete solidification of the particle by the choice of initial temperature distribution of the particle or the substrate. The results are listed without registration of 
Table 2.

Physical properties of steel used in computations.

\begin{tabular}{llll}
\hline$T_{0}(K)$ & $\lambda_{0}(W /(m \cdot K))$ & $c_{0}(J /(k g \cdot K))$ & $\rho_{0}\left(\mathrm{~kg} / \mathrm{m}^{3}\right)$ \\
\hline 293 & 52.0 & 588.1 & 7935.0 \\
600 & 39.7 & 611.9 & 8021.0 \\
1200 & 15.6 & 658.4 & 8193.0 \\
1473 & 4.68 & 679.6 & 8277.2 \\
\hline
\end{tabular}

Table 3.

Physical properties of particle $\mathrm{Al}_{2} \mathrm{O}_{3}$.

\begin{tabular}{ll}
\hline$\rho_{k}\left(\mathrm{~kg} / \mathrm{m}^{3}\right)$ & $\rho_{k}(T)=3692.97-0.0779 \cdot T$ \\
$c_{k}(\mathrm{~J} /(\mathrm{kg} \cdot \mathrm{K}))$ & $c_{k}(T)=464.357+1.368 \cdot T-0.00112 \cdot T^{2}$ \\
$\lambda_{k}(W /(\mathrm{m} \cdot K))$ & $\lambda_{k}(T)=39.898-0.11 \cdot T+1.4 \times 10^{4} \cdot T^{2}$ \\
$\beta$ & $\beta(T)=0.93-1.2 \times 10^{-4} \cdot T-7.9 \times 10^{-7} \cdot T^{2}$ \\
\hline
\end{tabular}

the oxide film.

Influence of the oxide films having different heat resistances on the contact temperature is reflected in Fig. 4 . In this case $\left.T_{k}(r, 0, t)\right|_{z=0^{+}} \neq\left. T_{0}(r, 0, t)\right|_{z=0^{-}}$ $(k=1,2)$. The results of numerical experiments show, that for thinner oxide film the temperature difference between the particle and the substrate on the contact line is smaller. Increasing of thickness of the oxide film leads to the increase of a jump of the contact temperature on the contact line.

Fig. 5 shows the contact temperature in the particle - substrate system at presence of an oxide film on the substrate surface and provided that the plasma is cooled by a substrate $\left(T_{g}=T\left(R_{\max }, z, t\right)\right)$.

In Figs. 6,7 the results of simulation of the contact temperature in the particle-substrate system in various instants without the registration of the thermal resistance of the oxide film are presented. In this case temperatures of the particle and the substrate in contact are equal.

Our research can be extended to the study of the thermal problems arising from impingement of the molten spherical particle onto the cold substrate during plasma spraying.

The proposed scheme of the solution of the thermal problem is applicable both in the case of a compressible fluid, and in case of an incompressible fluid.

\section{REFERENCES}

[1] H. Fukanuma and A. Ohmori. Behavior of molten droplets impinging on flat surfaces. In: Proc. of the 7th National Thermal Spray Conference 20-24 June 1994. Boston, Massachusetts, 1994.

[2] G. Gromyko, G. Zayats and A. Ilyuschenko. Numerical simulation of the coating structure under the plasma spraying. In: Proc. European Conference on Advances in Hard Materials Production, Turin, Italy, November 1999. Turin, Italy, 1999.

[3] G. Gromyko, G. Zayats and A. Ilyuschenko. Mathematical modeling of deformation 
and solidification of molten droplet on a flat substrate in a plasma spray process. J. of Thermal Spray, 5(47), $67-75,2001$.

[4] G. Gromyko, G. Zayats, A. Ilyuschenko and S. Kundas. On a modeling of the particle flattening and solidification in the plasma spraying. J. of Powder metallurgy, 22, 121 - 135, 1999.

[5] A. Ilyuschenko, S. Kundas, A. Dostanko and etc. The Processes of Coating Plasma Spraying: Theory and Practice. Armita, Minsk, 1999.

[6] V. Kudinov, P. Pekschev, V. Belaschenko and etc. Plotting of plasma coatings. Science, Moscow, 1990.

[7] H. Lui, E.J. Lavernia, R.H. Rangel, E. Muhlberger and A. Sickinger. Numerical investigation of micro-pore formation during substrate impact of molten droplets in spraying process. In: Proc. of the 7th National Thermal Spray Conference 20-24 June 1994. Boston, Massachusetts, 1994.

[8] O. Solonenko and V. Smirnov. Collision of melt droplet with a surface. Theory and model experiment. Reports RAS, tech. phys., 1998.

\section{Apie plonos plèvelès oksidaciją terminiame poveikyje pagrindinių dalelių sistemoje, kai turime plazmini purškimą}

G. Gromyko, G. Zayats

Šiame straipsnyje pateikiamas terminių procesu matematinis modelis pagrindinių detalių sistemoje, kai turime plazmini purškimą. Naudojant ribines temperatūros sąlygas abiem dalelèms ir pagrindo sritims išspręsta energijos lygtis. Svarbiausia tyrimų kryptis yra temperatūros poveikyje dalelių sąveika su pagrindu. Modeliuojamas plonos plèvelès oksidacijos poveikis pagrindo paviršiui, atsižvelgiant i šiluminès oksidacijos pasipriešinimą. Išnagrinètas keleto svarbiu parametru poveikis šiluminu procesu perdavime. Skaitiniai algoritmai realizuoti panaudojant keletą programų. 